\title{
QUALITY IMPROVEMENT OF A SAFETY VALVE WITH THE USE OF NUMERICAL AND EXPERIMENTAL STUDIES
}

doi: 10.2478/cqpi-2019-0051

Date of submission of the article to the Editor: 08/04/2019

Date of acceptance of the article by the Editor: 28/05/2019

Grzegorz Filo ${ }^{1}$ - orcid id: 0000-0003-0848-6124

Mariusz Domagała ${ }^{1}$ - orcid id: 0000-0001-9642-6142

Paweł Lempa ${ }^{1}$ - orcid id: 0000-0002-9421-440X

Joanna Fabiś-Domagała ${ }^{1}$ - orcid id: 0000-0003-2811-1100

Dominik Kwiatkowski ${ }^{1}$ - orcid id: 0000-0003-4415-6704

Hassan Momeni ${ }^{2}$ - orcid id: 0000-0002-3535-5413

${ }^{1}$ Cracow University of Technology, Faculty of Mechanical Engineering, Jana Pawla II 37, Cracow, Poland

${ }^{2}$ Western Norway University of Applied Sciences, Inndalsveien 28, 5063 Bergen, Norway

Abstract: This article presents results of numerical modelling, simulation and test bench experiments of a hydraulic direct-acting relief valve was used as a safety valve. The analyzed safety valve was placed in a system consisting of a fixed-speed pump, a control valve, a hydraulic cylinder as an actuator and a second pressure valve in the load line used as a payload generator for the cylinder. In the first step mathematical model of the system was formulated in the form of a system of ordinary differential equations. Next, simulation model was created in Matlab/Simulink. Simulations were carried out for different values of the actuator payload. The obtained results include time series of pressure, flow rate and displacement of the actuator piston. In order to confirm simulation results, a test bench was built and series of experiments were carried out. High compliance of simulation and laboratory results was obtained. It was confirmed that the proposed solution with the relief valve used as a safety valve fulfills its task of protecting the hydraulic system from excessive pressure increase.

Keywords: hydraulic system protection, safety valve, relief valve, numerical modelling, test bench experiments

\section{INTRODUCTION}

Nowadays, with the development of high-pressure hydraulic systems, the issue of protection against damage or destruction is of special importance. Main purpose of a safety valve included in a hydraulic system is to protect the system against excessive pressure increase. Usually, the safety valve is inactive during the normal operation, which means that the flow through the valve is shut off. It opens only under exceptional circumstances. Due to their necessity, safety valves are often subjects of analysis and research. A detailed review of different safety valve configurations, including actuator 
and solenoid/positioner combinations that can be used in practical applications was given by Miller and Bredemyer (Miller and Bredemyer, 2007). The authors presented failure rate and reliability studies, data associated with the various component combinations and impact of the selections on the safety integrity level (SIL) verification. An analysis of the effect related to the gas expansion throughout safety relief valves was carried out numerically and experimentally by Dossena (Dossena et al., 2013). The main conclusion was that particular care must be taken when a safety valve operates with a fluid characterized by a specific heat ratio greater than the one of the fluid used during the type testing. Investigations of a safety valve characteristics in a low-pressure, two-phase flow system were also carried out by Dempster (Dempster and Alshaikh, 2015). Results of the tested range of conditions indicate that the flow and force characteristics of the safety valve are significantly influenced by the flow rate. Modelling and analysis of safety valves using computational fluid dynamics (CFD) and fluidstructure interaction (FSI) techniques related to a spring-loaded pressure valve was the subject of Song's article (Song et al., 2015). Similarly, Scuro (Scuro et al., 2018) provided CFD analysis of a directly-operated safety relief valve, while Beune (Beune et al., 2012) analyzed opening of a high-pressure safety valves by the means of both CFD and $\mathrm{FSI}$.

Some of the research concern specific applications of safety valves including special fluids and environmental conditions. The effectiveness of a fire pressure safety valves (PSV) in the offshore oil and gas installation when the process equipment is exposed to a fire was investigated by Bjerre (Bjerre et al., 2017). Simulations of several typical offshore pressure vessels were performed using the VessFire commercial software. On the contrary, dynamic simulation and validation of a safety valve for cryogenic flight tanks was carried out by Manimaran (Manimaran et al., 2016). The authors presented mathematical modelling, simulations and laboratory experiments on an inverted type pilot-operated vent and safety valve. Research on safety valves sometimes also requires the analysis of parameters such as viscosity (Moncalvo and Friedel, 2010), the Reynolds number (Dossena et al., 2017) or pressure oscillations and vibrations (Galbally et al., 2015).

This article provides numerical and experimental study of performance of a relief valve used as a safety valve. The valve was installed in a hydraulic system with a fixed-speed pump, a control valve and a hydraulic cylinder. Methodology of mathematical modelling and simulation is similar to the one used by the authors for obtaining characteristics of a proportional flow control valve (Lisowski and Filo, 2016) and analyzing a flow coefficient (Lisowski and Filo, 2017).

\section{MATHEMATICAL MODEL AND SIMULATIONS}

Mathematical model of the system is based on the continuity equation for compressible fluid, the Bernoulli's equation, the equation of hydraulic cylinder motion and geometrical dependencies. Scheme of the modelled system is shown in Fig. 1. Volumetric flow rate of the pump $Q_{p}$ is constant and equal to the nominal value $Q_{p n o m}$ except the start-up time $t_{\text {start }}=0.2 \mathrm{~s}$, when increases linearly:

$$
Q_{p}(\mathrm{t})=\left\{\begin{array}{l}
Q_{\text {pnom }} \cdot \frac{t}{t_{\text {start }}}, \text { when } t<t_{\text {start }} \\
Q_{\text {pnom }} \text { otherwise } .
\end{array}\right.
$$




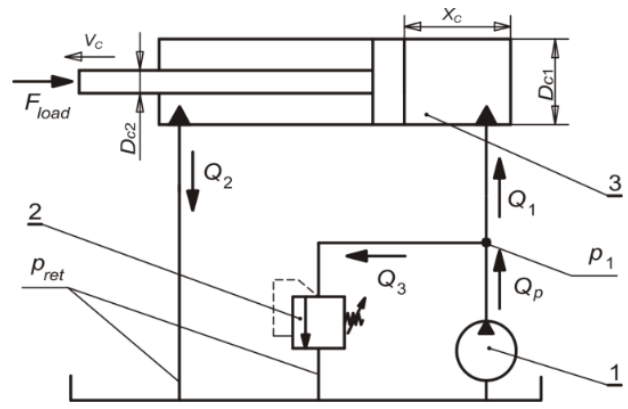

Fig. 1. Modelled hydraulic system: 1 - pump, 2 - safety valve, 3 - hydraulic cylinder, $F_{\text {load }}$ - payload force, $Q_{p}, Q_{1}, Q_{2}, Q_{3}$ - flow rate, $p_{1}$, $p_{\text {ret }}$ - pressure, $D_{c 1}, D_{c 2}$ - diameter

The supply line pressure $p_{1}$ can be calculated from the formula:

$$
\frac{d p_{1}(t)}{d t}=\frac{B}{V_{1}+A_{c 1} \cdot x_{c}(t)}\left(Q_{p}(t)-Q_{1}(t)-Q_{3}(t)\right),
$$

where $B$-fluid bulk modulus, $V_{1}$ - initial volume of the supply line, $A_{c 1}$-cylinder crosssectional area, $x_{C}$ - cylinder piston position, $Q_{1}$ - hydraulic cylinder inflow, $Q_{3}$ - safety valve flow rate. The return line pressure $p_{\text {ret }}$ is assumed to be approximately constant $p_{\text {ret }}=0.1 \mathrm{MPa}$. Determination of the unknown flow rate values $Q_{1}(t)$ and $Q_{2}(t)$ requires the hydraulic cylinder piston equation of motion to be formulated:

$$
\begin{gathered}
v_{c}(t)=\frac{d x_{c}(t)}{d t} \\
\frac{d v_{c}(t)}{d t}=\frac{1}{m_{c}}\left(p_{1}(t) \cdot A_{c 1}-p_{r e t}\left(A_{c 1}-A_{c 2}\right)-v_{c}(t) \cdot \alpha_{c}-F_{\text {load }}\right),
\end{gathered}
$$

where $m_{c}$ stands for mass of the movable part of hydraulic cylinder (piston and rod), $\alpha_{c}$ is a damping factor, $A_{c 2}$ is the cross-sectional area of the rod and $F_{\text {load }}$ is a payload force. Value of the hydraulic cylinder piston velocity $v_{c}$ derived from Eq. (4) can be used to calculate $Q_{1}(t)$ and $Q_{2}(t)$ :

$$
\begin{gathered}
Q_{1}(t)=A_{c 1} \cdot v_{c}(t), \\
Q_{2}(t)=\left(A_{c 1}-A_{c 2}\right) \cdot v_{c}(t) .
\end{gathered}
$$

Next, flow rate through the safety valve $Q_{3}(t)$ is based on a valve piston position $x_{3}(t)$, whose equation of motion has the following form:

$$
\begin{gathered}
v_{3}(t)=\frac{d x_{3}(t)}{d t} \\
\frac{d v_{3}(t)}{d t}=\frac{1}{m_{3}}\left[\left(p_{1}(t)-p_{r e t}\right) \cdot \frac{\pi D_{3}{ }^{2}}{4}-v_{3}(t) \cdot \alpha_{3}-x_{3}(t) \cdot k_{3}-F_{s 3}\right] .
\end{gathered}
$$

The safety valve parameters have been marked using index 3 , respectively: $m_{3}$ and $D_{3}$ - mass and diameter of the valve piston, $\alpha_{3}$-damping coefficient, $k_{3}$-spring stiffness, $F_{s 3}$-initial spring tension. The initial spring tension $F_{s 3}$ provides opening the valve when pressure in the supply line exceeds $15 \mathrm{MPa}$. In this case a cylindrical gap of diameter $D_{3}$ and width $x_{3}$ is formed around the piston. Hence, the flow rate $Q_{3}(t)$ can be calculated on the basis of the Bernoulli's equation:

$$
Q_{3}(t)=c_{3} \cdot A_{3}(t) \cdot \sqrt{\frac{2\left(p_{1}-p_{r e t}\right)}{\rho}} .
$$

High value of the initial spring tension ensures that the requirement of the equation applicability: $p_{1}>p_{\text {ret }}$ is always fulfilled. The contraction factor was set a fixed value $c_{3}=0.65$ and similarly the fluid density $\rho=840 \mathrm{~kg} \mathrm{~m}^{-3}$. Area of the gap $A_{3}(t)$ depends on the valve spool position: 


$$
A_{3}(t)=\pi \cdot D_{3} \cdot x_{3}(t) .
$$

The formulated system of 10 equations defines the following time-variable parameters of the analyzed system: flow rates $Q_{p}, Q_{1}, Q_{2}, Q_{3}$, pressure $p_{1}$, velocities $v_{c}, v_{3}$, positions $x_{c}, x_{3}$ and gap area $A_{3}$. In the next step the presented equations were used to build a block diagram simulation model in Simulink.

Main diagram of the created simulation model is shown in Fig. 2, while Table 1 presents values of some significant geometrical and physical parameters which were used in the simulations. It arises from the figure that main block represent the individual components of the system: pump, safety valve, hydraulic cylinder and supply line. The blocks are connected using pressure and flow rate signals. There are two adjustable parameters in the editable blocks: the payload force in $\mathbf{F}$ _load and the return line pressure in p_ret, respectively.

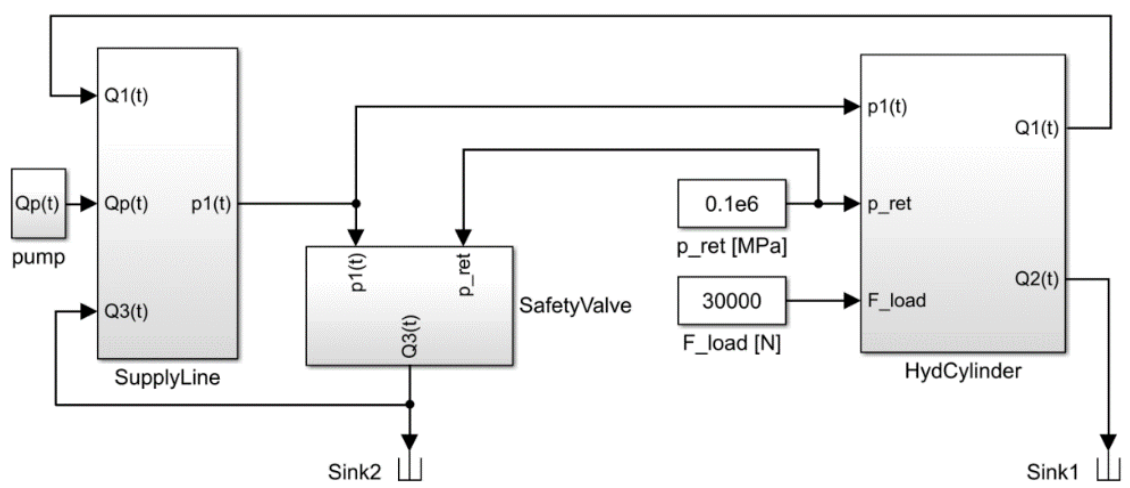

Fig. 2. Block diagram of the simulation model

Table 1

Physical and geometrical parameters of the simulation model

\begin{tabular}{|l|l|l|l|}
\hline \multicolumn{1}{|c|}{ Name } & \multicolumn{1}{c|}{ Denotation } & \multicolumn{1}{c|}{ Value } & \multicolumn{1}{c|}{ Unit } \\
\hline Nominal pump delivery & $Q_{\text {nnom }}$ & 15 & $\mathrm{dm}^{3} \mathrm{~min}^{-1}$ \\
\hline Cylinder and piston rod diameter & $D_{c 1} / D_{c 2}$ & $60 / 32$ & $\mathrm{~mm}$ \\
\hline Safety valve piston diameter & $D_{3}$ & 12 & $\mathrm{~mm}$ \\
\hline Safety valve initial spring tension & $F_{s 3}$ & 1680 & $\mathrm{~N}$ \\
\hline Safety valve opening pressure & $p_{3}$ & 15 & $\mathrm{MPa}$ \\
\hline Fluid density & $\rho$ & 840 & $\mathrm{~kg} \mathrm{~m}{ }^{-3}$ \\
\hline Fluid bulk modulus & $B$ & 1000 & $\mathrm{GPa}$ \\
\hline Return line pressure & $p_{\text {ret }}$ & 0.1 & $\mathrm{MPa}$ \\
\hline
\end{tabular}

The assumed values of the system parameters ensure correct operation with the payload below $40 \mathrm{kN}$. Hence, in order to check operation of the safety valve, simulation tests were carried out with the payload up to $45 \mathrm{kN}$. Example results obtained for 20, 40, 42.5 and $45 \mathrm{kN}$ are shown in Fig. 3.

It arises from the figure, that in case when the payload force is $40 \mathrm{kN}$ or less, the safety valve is switched off and the entire flow rate is directed to the cylinder (Fig.3a and Fig.3b). However, the safety valve opens when the cylinder piston reaches the end position (time $=5.8 \mathrm{~s}$ ). Case (c) illustrates situation when the pressure is slightly above the acceptable value and the safety valve is partly open $\left(Q_{3}=12.2 \mathrm{dm}^{3} \mathrm{~min}^{-1}\right)$. Finally, case d) represents the situation when the payload force is too high. Hence, the entire fluid flows through the safety valve while the cylinder piston does not move. 

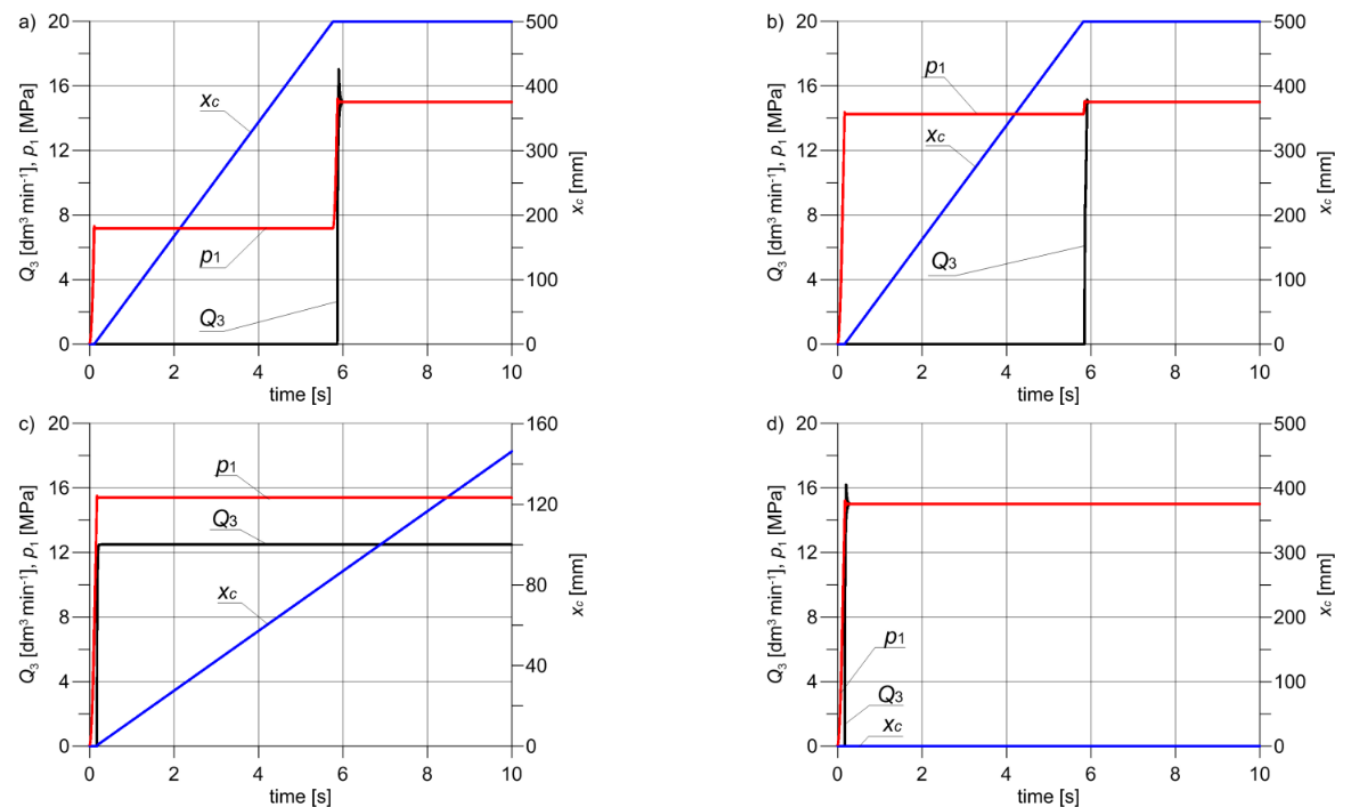

Fig. 3. Simulation results including supply line pressure $p_{1}$, cylinder piston position $x_{c}$ and safety valve flow rate $Q_{3}$; a) $F_{\text {load }}=20 \mathrm{kN}$, b) $F_{\text {load }}=40 \mathrm{kN}$, c) $F_{\text {load }}=42.5 \mathrm{kN}$, d) $F_{\text {load }}=45 \mathrm{kN}$

\section{TEST BENCH EXPERIMENTS}

The obtained simulation results were next verified at the test bench, which scheme shows Fig. 4 and front view presents Fig. 5.

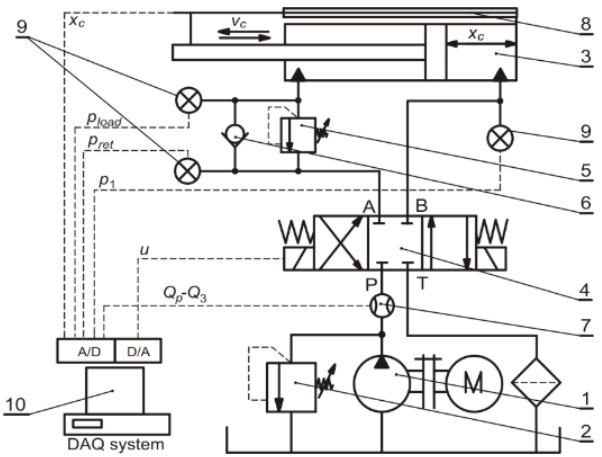

Fig. 4. Test bench scheme: 1 - pump, 2 - safety valve, 3 - hydraulic cylinder, 4 - control valve, 5 - relief valve, 6 - check valve, 7 - flow meter, 8 - displacement transducer, 9 - pressure transducer, 10 - data acquisition system

In addition to the main components which are: a pump (1) a safety valve (2) and a hydraulic cylinder (3) there is also a load-generating relief valve (5) and two elements providing the return movement: a control valve (4) and a check valve (6). The measuring system include a flow meter (7) a displacement transducer (8) and three pressure transducers (9). Change of the piston movement direction is realized by means of control signal $u$. The payload force $F_{\text {load }}$ can be calculated on the basis of the difference between the average values of the pressures: $A V G\left(p_{\text {load }}\right)$ and $A V G\left(p_{\text {ret }}\right)$ measured during the cylinder piston movement.

$$
F_{\text {load }}=\left(A V G\left(p_{\text {load }}(t)\right)-A V G\left(p_{\text {ret }}(t)\right)\right)\left(A_{c 1}-A_{c 2}\right) .
$$

Results of laboratory experiments in the form of pressure charts $p_{1}(t), p_{\text {load }}(t), p_{\text {ret }}(t)$, flow rate $Q_{1}(t)=Q_{p}(t)-Q_{3}(t)$ and the piston displacement $x_{c}(t)$ are shown in Fig. 6 . 


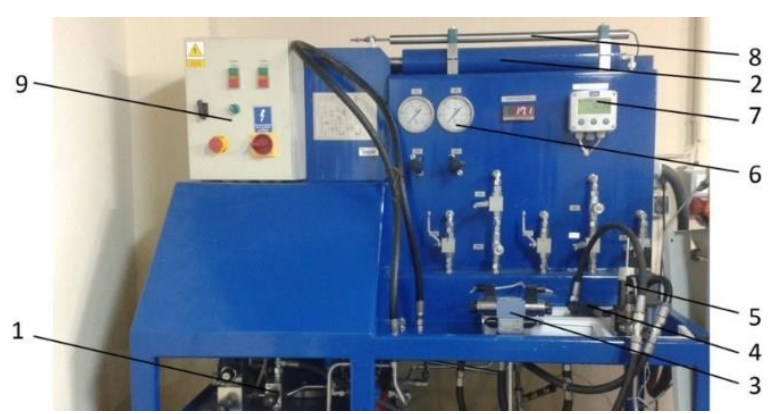

Fig. 5. Test bench front view; 1 - safety valve, 2 - hydraulic cylinder, 3 - control valve, 4 check valve, 5 - relief valve, 6 - $p_{1}$ pressure gauge, 7 - flow meter display, 8 - displacement transducer, 9 - control panel
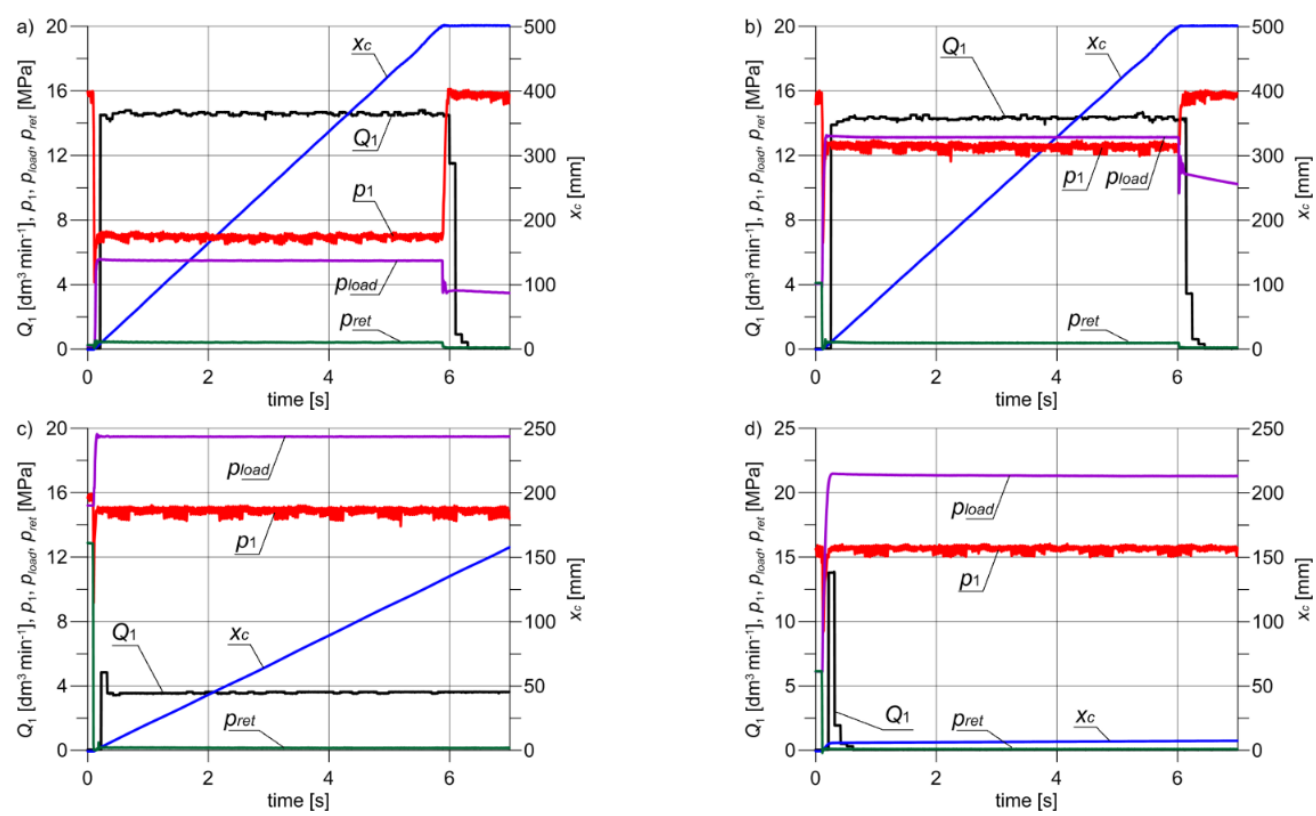

Fig. 6. Results of the test bench experiments: a) $F_{\text {load }}=16.3 \mathrm{kN}$, b) $F_{\text {load }}=32.5 \mathrm{kN}$,

c) $\left.F_{\text {load }}=40.9 \mathrm{kN}, \mathrm{d}\right) F_{\text {load }}=43.0 \mathrm{kN}$

As arises from the presented charts, laboratory experiments confirmed simulation results. Having the payload force equal to $16.3 \mathrm{kN}$ and $32.5 \mathrm{kN}$, the safety valve is closed. If the force exceeds the threshold value $\left(F_{\text {load }}=40.9 \mathrm{kN}\right)$, the valve opens to some extent and reduces value of the $Q_{1}$ flow rate. For $F_{\text {load }}=43.0 \mathrm{kN}$ the valve is fully open and entire flow passes through it.

\section{SUMMARY}

The presented article concerns modelling and laboratory testing of a safety valve in a hydraulic system. Main task of the valve is to protect the system from the effects of a sudden excessive pressure increase. Two cases of the pressure increase were tested: the first one concerned the situation when hydraulic cylinder piston reached its end position, while the second one resulted from the excessive payload force. Results of both simulations and laboratory experiments in each case indicate, that the proposed relief valve protects the system to a sufficient degree. The results of experimental research coincide with simulations and thus prove the correctness of the mathematical model and the adopted modelling methodology. 
The results presented in this paper may be interested for researchers and developers working on hydraulic components (Krawczyk et al., 2018) or using them in their own infrastructure e.g. biotechnology (Skrzypczak-Pietraszek et al., 2018). The approach to aligning experimental research and the numerical model may be of interest for any researcher using surrogate models in his/her own practice e.g. materials science (Szczotok et al., 2018), surface machining (Gadek-Moszczak et al., 2014; Ulewicz and Selejdak, 2018; Pliszka et al., 2018), protective coatings (Radek et al., 2018), power plants (Osocha et al., 2018) or even in museum revitalization (Karpisz and Kielbus, 2019), while others use specific methods to quantify uncertainty (Pietraszek et al., 2016). The usefulness of the presented research can also be inspiring for effective university management and commercialization of these studies (Kozien and Kozien, 2017; Kozien, 2017).

\section{REFERENCES}

Beune, A., Kuerten, J.G.M., van Heumen, M.P.C., 2012. CFD analysis with fluidstructure interaction of opening high-pressure safety valves, Computers \& Fluids 64, 108-116, DOI:10.1016/j.compfluid.2012.05.010.

Bjerre, M., Eriksen, J.G.I., Andreasen, A., Stegelmann, C., Mando, M., 2017. Analysis of Pressure Safety Valves for fire protection on offshore oil and gas installations, Process Safety and Env. Protection 105, 60-68, DOI: 10.1016/j.psep.2016.10.008.

Dempster, W., Alshaikh, M., 2015. An Investigation of the Two Phase Flow and Force Characteristics of a Safety Valve, Procedia Engineering 130, 77-86, DOI: 10.1016/j.proeng.2015.12.177.

Dossena, V., Franchina, N., Savini, M., Marinoni, F., Cecchi, F., Bassi, F., 2017. Reynolds number effects on the performance of safety valves operating with incompressible flows, Journal of Loss Prevention in the Process Industries 49, 525535, DOI: 10.1016/j.jp.2017.05.020.

Dossena, V., Marinoni, F., Bassi, F., Franchina, N., Savini, M., 2013. Numerical and experimental investigation on the performance of safety valves operating with different gases, International Journal of Pressure Vessels and Piping 104, 21-29, DOI: 10.1016/j.ijpvp.2013.01.002.

Gadek-Moszczak, A., Radek, N., Wronski, S., Tarasiuk, J., 2014. Application the 3D image analysis techniques for assessment the quality of material surface layer before and after laser treatment. Adv. Mat. Res. Switz., 874, 133-138. DOI: 10.4028/www.scientific.net/AMR.874.133

Galbally, D., Garcia, G., Hernando, J., de Dios Sanchez, J., 2015. Analysis of pressure oscillations and safety relief valve vibrations in the main steam system of a Boiling Water Reactor, Nuclear Engineering and Design 293, 258-271, DOI: 10.1016/j.nucengdes.2015.08.005.

Karpisz, D., Kielbus, A., 2019. The Revitalization of Radar System as a Case of Functional and Information Security Problems. System Safety: Human - Technical Facility - Environment, 1, 692-699. DOI: 10.2478/czoto-2019-0088

Kozien, E., 2017. Identification of stage phase growth in the checklist method using different statistical parameters. $20^{\text {th }}$ Int. Sci. Conf. Economic and Social Development, Prague, Varazdin, 538-545.

Kozien, E., Kozien, A., 2017. Commercialization of scientific research results and transfer knowledge and technologies to economy as determinants of development 
of universities and enterprises in Poland - legal and economic perspective. $26^{\text {th }}$ Int. Sci. Conf. Economic and Social Development, Zagreb, Varazdin, 326-335.

Krawczyk, J., Sobczyk, A., Stryczek, J., Walczak, P., 2018. Tests of New Methods of Manufacturing Elements for Water Hydraulics. Materials Research Proceedings, 5, 200-205. DOI: 10.21741/9781945291814-35

Lisowski E., Filo G., 2016. CFD analysis of the characteristics of a proportional flow control valve with an innovative opening shape, Energy Conversion and Management 123, 15-28, doi:10.1016/j.enconman.2016.06.025.

Lisowski, E., Filo, G., 2017. Analysis of a proportional control valve flow coefficient with the usage of a CFD method, Flow Measurement and Instrumentation 53, 269-278, DOI: 10.1016/j.flowmeasinst.2016.12.009.

Manimaran, A., Hiremath, S.S., Shekhar, P., 2016. Dynamic Simulation and Validation of a Vent and Safety Valve for Cryogenic Flight Tanks, Procedia Technology 25, 1320-1334, DOI:10.1016/j.protcy.2016.08.232.

Miller, C., Bredemyer, L., 2007. Innovative safety valve selection techniques and data, Journal of Hazardous Materials 142, 685-688, doi: 10.1016/j.jhazmat.2006.06.072.

Moncalvo, D., Friedel, L., 2010. A viscosity correction factor for shear-thinning liquid flows in safety valves, Journal of Loss Prevention in the Process Industries 23, 289293, DOI: 10.1016/j.jp.2009.10.008.

Osocha, P., 2018. Calculation of Residual Life for P91 Material Based on Creep Rate and Time to Rupture. Materials Research Proceedings, 5, 177-182. DOI: 10.21741/9781945291814-31

Pietraszek, J., Kolomycki, M., Szczotok, A., Dwornicka, R., 2016. The fuzzy approach to assessment of ANOVA results. ICCCI 2016: Conf. Comp. Collective Intell. Springer, 260-268. DOI: 10.1007/978-3-319-45243-2_24

Pliszka, I., Radek, N., Gadek-Moszczak, A., Fabian, P., Paraska, O., 2018. Surface Improvement by WC-Cu Electro-Spark Coatings with Laser Modification. Materials Research Proceedings, 5, 237-242. DOI: 10.21741/9781945291814-42

Radek, N., Pasieczynski, L., Makrenek, M., Dudek, A., 2018. Mechanical Properties of Anti-Graffiti Coating Systems used in the Railway Industry. Materials Research Proceedings, 5, 243-247. DOI: 10.21741/9781945291814-43

Scuro, N.L., Angelo, E., Angelo, G., Andrade, D.A., 2018. A CFD analysis of the flow dynamics of a directly-operated safety relief valve, Nuclear Engineering and Design 328, 321-332, DOI: 10.1016/j.nucengdes.2018.01.024.

Skrzypczak-Pietraszek, E., Reiss, K., Zmudzki, P., Pietraszek, J., 2018. Enhanced accumulation of harpagide and 8-O-acetyl-harpagide in Melittis melissophyllum L. agitated shoot cultures analyzed by UPLC-MS/MS. PLoS ONE 2018, 13, art. e0202556. DOI: 10.1371/journal.pone.020255610.1371/journal.pone.0202556

Song, X.G., Wang, L.T., Park, Y.C., Sun, W., 2015. A Fluid-Structure Interaction Analysis of the Spring-Loaded Pressure Safety Valve during Popping Off, Procedia Engineering 130, 87-94, DOI: 10.1016/j.proeng.2015.12.178.

Szczotok, A., Radek, N., Dwornicka, R., 2018. Effect of the induction hardening on microstructures of the selected steels. METAL 2018: $27^{\text {th }}$ Int. Conf. Metallurgy and Materials. Ostrava, Tanger, 1264-1269.

Ulewicz, R., Selejdak, R., 2018. Impact of Laser Machining on the Structure and Properties of Tool Steels. Materials Research Proceeding, 5, 37-40. DOI: DOI: 10.21741/9781945291814-7 